\title{
A Framework for Innovation Outsourcing
}

\section{Shahwar Rehman, Ashutosh Tiwari, Christopher Turner * and Leon Williams}

Cranfield University, Bedford, Bedfordshire, MK43 0AL, UK, Email: c.j.turner@cranfield.ac.uk *Corresponding author

\section{Abstract}

This paper proposes a framework for the facilitation of organisational capability for outsourcing innovation, enabling firms to take advantage of its many benefits, (e.g., reduced costs, increased flexibility, access to better expertise and increased business focus), whilst mitigating its risks. In this framework a generic holistic model is developed to aid firms to successfully outsource innovation. The model is realised in two stages using a qualitative theory-building research design. The initial stage develops a preliminary model which is subsequently validated and refined during the second stage. The propositions which form the preliminary model are deductively explored to identify whether they also exist in a second data set. A semi-structured interview survey is executed with the aid of a rich picture survey instrument to gather data for this purpose.

The model developed by this study describes innovation outsourcing as an open system of interrelated activities that takes established company strategy, (in terms of people, organisational structures, environment, and technology), and transforms it into improved firm performance through innovation. The model achieves this through a three-stage process which enables the alignment of capability to outsourced innovation activity, and makes actual performance outcomes, rather than expected benefits, the focus of innovation outsourcing aims.

Keywords: Innovation Outsourcing, Business Strategy, Open Innovation,

Biographical notes: Shahwar Rehman is a PhD student in the Manufacturing and Materials Department at Cranfield University.

Ashutosh Tiwari is Head of the Manufacturing Informatics Centre and leads a research group in manufacturing informatics within this Centre. Professor Tiwari's research interests focus on the application of product design optimisation, informatics techniques to manufacturing and business process optimisation.

Chris Turner is a Research Fellow in the Manufacturing and Materials Department at Cranfield University. His current research interests include Business Process Management and Optimisation.

Leon Williams is the Director of Centre for Competitive Creative Design (C4D) at Cranfield University with a specialised area of research in Prestige Design and Creative Innovation. 


\section{Introduction}

In today's business environment the ever-increasing complexity and cost of innovation efforts is driving many firms to seek increased effectiveness and efficiency of their R\&D functions. A solution considered by some firms is to apply the practice of outsourcing to their innovation functions. This is being encouraged by a combination of various macro factors, including: the growth in the number of specialist markets worldwide; growth in the global availability of knowledge workers and knowledge bases; growth in global interaction capabilities supported by enhanced information technologies, and; relaxation of many economic and political barriers worldwide (Quinn, 2000). Innovation as an activity wholly undertaken within the firm is steadily being eroded with the growing evidence that it is increasingly being outsourced. Firms considering such a strategy must develop capabilities for managing innovation outsourcing, taking advantage of its many benefits, (e.g., reduced costs, increased flexibility, access to better expertise and increased business focus), whilst mitigating its risks.

This qualitative study concerns the facilitation of organisational capability for the management of innovation outsourcing. To avoid any misinterpretation, use of the term 'innovation outsourcing' is now clarified. The term is used to refer to the outsourcing by an organisation of its innovation activity, i.e., outsourcing of innovation. The terms 'innovation outsourcing' and 'outsourcing of innovation' are used interchangeably. The term does not refer to new paradigms, products or processes concerning the sourcing of goods and services previously produced inside the boundary of an organisation, i.e., innovation within outsourcing. Use of the term 'innovation outsourcing' within this research encompasses the paradigm of open innovation which emphasises the potential of external resources to create value and promotes the building of a firms capability to take advantage of its benefits (Chesbrough, 2003) (Huizingh, 2011) including cross cultural aspects of outsourcing (Dabrowska and Savitskaya, 2014). Whereas open innovation is no more than a paradigm, '... is not ipso facto a recipe for outsourcing R\&D' (Chesbrough and Crowther, 2006), the term 'innovation outsourcing' is used to extend the paradigm to the process of its realisation, encompassing its determinants, selection, implementation and outcomes. The view adopted in this research is that innovation outsourcing is a strategic decision involving the prerequisites, processes and implications by which a firm substitutes or complements its internal innovation activity with that sourced from outside its boundaries.

To put into context the need for proper facilitation of organisational capability for the management of innovation outsourcing, the following case provides an illustration. Between 1990 and 2002, the motor manufacturer Fiat outsourced a large proportion of the research and development of its product design and engineering to numerous suppliers (Ciravegna and Maielli, 2011). The result of this highly outsourced R\&D strategy was an erosion of Fiat's capabilities, poor products and rapidly declining sales. So, how is it that firms with the resources of Fiat can make decisions which potentially put the organisation at risk? A failure 
by Fiat's management to put in place an effective business model resulted in: too much focus on cost; outsourcing core innovation activity; erosion of architectural knowledge, and; a failure to absorb and integrate new knowledge (Ciravegna and Maielli, 2011).

Differentiating core value activities when outsourcing is critical. Not doing so may in the opinion of Elango (2008) result in the hollowing out of the firm's competencies leading to a diminished strategic position. This risk is exemplified by Lowman et al. (2014) who point to the potential loss of learning gained in the new product development cycle; where insights into the design of products are lost from the outsourcing organisation. The analysis of risk as a whole in outsourcing contracts has been examined by Chou and Chou (2009). These authors identify risks in information system outsourcing contracts in terms of overall lifecycle concluding that a costing approach that takes account of the whole life of the contracted system mitigates risks and the outset Chou and Chou (2009). The governance of such outsourcing contracts has been researched by Oshri et al. (2015), stating that strategic considerations about how outsourcing will be managed over the lifetime of the arrangement. A distinction is also made by Breunig and Bakhtiari (2013) between outsourcing primarily for cost reduction and that for innovation purposes. In a study of Australian forms the authors noted that outsourcing without innovation is damaging to the firm's future innovation capabilities (Breunig and Bakhtiari, 2013).

The overall aim of this research is to provide a study which identifies the status of innovation outsourcing knowledge. In particular this research aim to fulfil the following objectives:

1. Undertake a state-of-the-art review to define a baseline of knowledge relating to innovation outsourcing as a management discipline.

2. Develop a validated holistic model through the identification \& organisation, and refinement of innovation outsourcing capabilities for performance.

- Inductively develop an archetype framework for successfully outsourcing innovation.

- Develop a preliminary innovation outsourcing model by exploring the framework to identify the associations between capabilities and performance.

- Design and administer a survey to gather appropriate data with which to test the preliminary model.

- Analyse the results of the survey to deductively validate \& refine the model.

3. Discuss the potential benefits of utilising the model to outsource innovation.

The following section of this paper explores the background literature comprising this core of this research.

\section{Background Literature}

A review and analysis of the extant literature has been undertaken to define a baseline of research within the innovation outsourcing domain. In total 248 papers concerning 
innovation outsourcing, spanning a publication period of 22 years (1990-2013), have been consulted during this research. Table 1 details the journals most prolific for this subject and for this review. Using template analysis an archetypal framework has been developed for organising and integrating relevant literature.

Table 1: Journals most prolific within the innovation outsourcing domain

\begin{tabular}{|c|c|}
\hline Journal & No. of Papers \\
\hline Research Technology Management & 20 \\
\hline R\&D Management & 14 \\
\hline Industry \& Innovation & 11 \\
\hline International Journal of Imovation Management & 11 \\
\hline Research Policy & 9 \\
\hline International Joumal of Technology Management & 7 \\
\hline Journa of Product Innovation Management & 7 \\
\hline Technovation & 7 \\
\hline Havard Business Review & 6 \\
\hline Journa of International Management & 6 \\
\hline MIT Sloan Management Review & 6 \\
\hline IEEE Transadions on Engineering Management & 5 \\
\hline International Joumal of Operations \& Production Management & 4 \\
\hline Strategic Managem ent Journal & 4 \\
\hline Industrial \& Corporate Change & 3 \\
\hline International Joumal of Imovation \& Technology Management & 3 \\
\hline International Journal of Servioes Technology and Managemert & 3 \\
\hline Journa of Management Studies & 3 \\
\hline Journa of Operations Management & 3 \\
\hline Management Decision & 3 \\
\hline Orgarization Science & 3 \\
\hline Techndogy Analysis \& Strategc Management & 3 \\
\hline Creativity \& I movation Management & 2 \\
\hline Economics of Imovation \& New Technology & 2 \\
\hline European Management Journal & 2 \\
\hline Hum an Systems Management & 2 \\
\hline Industrial Marketing Management & 2 \\
\hline International Business Review & 2 \\
\hline International Joumal of Entrepreneurship \& Innovation Management & 2 \\
\hline Journa of International Business Studies & 2 \\
\hline Journa of International Economics & 2 \\
\hline Managerial \& Decision Economics & 2 \\
\hline Mokinsey Quarterly & 2 \\
\hline Quality Progress & 2 \\
\hline Review of I rternational Economics & 2 \\
\hline Strategic Outsourcing: an International Joumal & 2 \\
\hline Strudural Change \& Economic Dynamics & 2 \\
\hline Other Joumals & 1 Each \\
\hline
\end{tabular}

There does not exist a widely accepted definition of innovation outsourcing. In forming a definition the following approach was taken. The theory or theories referenced by each paper included in the review have been identified. A single paper may use more than one reference theory and all that are referenced are noted. Where a paper does not reference a theory nor apply a theoretical foundation it is categorised as $n / a$. 
Of the major works on outsource the following are particularly pertinent. Transaction cost economics TCE theory (Williamson, 1975) (Williamson, 1985) is the foundation of the 'makebuy' management decision which traditionally determines the boundary of the firm. Internalisation is an economic theory (Coase, 1937) which considers alternative contractual arrangements to explain the choice of activities to coordinate different economic activity. Resource-based theories (Penrose, 1959) used within the literature assert that competitive advantage is attained if a firm possesses resources not held by others. An example of the use of resource-based theories within the literature is to explain innovation outsourcing capability as a source of competitive advantage (O'Regan and Kling, 2011). To avoid confusion, the similarities and differences of innovation outsourcing to open innovation are highlighted. Core competency theory (Prahalad and Hamel, 1990) (Prahalad and Hamel, 1994) states that firms should protect and nurture those activities which they do better than anyone else. It is cited in the literature as reason to outsource activities that are non-core and focus on activities where the firm has a distinct advantage. Open innovation (Chesbrough, 2003) is a new paradigm embodied in six principles which asserts that innovations do not necessarily have to originate from within the bounds of the firm to be profitable. Innovation outsourcing incorporates the paradigm of open innovation and extends it to the process of its realisation, encompassing its determinants, selection, implementation and outcomes.

A definition is synthesised from an analysis of the domain's key characteristics and is stated below.

'a strategic decision involving the antecedents, processes and implications by which a firm substitutes or complements its internal innovation activity with that sourced from outside its boundaries'

There has been a growing interest in the innovation outsourcing phenomenon amongst academics, researchers and practitioners; a phenomenon that has existed for more than two decades. It has widespread interest across several discipline areas and countries. Innovation outsourcing is a widespread firm-centric management discipline that is multivariable. The innovation outsourcing literature is diffuse, studies have low specificity. The literature adopts a wide variety of research philosophies, research approaches, and research strategies. The literature adopts a variety of time horizons and research purposes. For example the work of Roy, S. and Sivakumar (2012) explores the outsourcing of knowledge based services, highlighting the need to identify the level of tacit knowledge that must be managed during the outsourcing process. The vast majority of the studies associated with innovation outsourcing adopt a narrow focus. Only seven papers (Ciravegna and Maielli, 2011) (Zirpoli and Becker, 2011a) (Zirpoli and Becker, 2011b) (Roy and Sivakumar, 2011) (Azadegan and Dooley, 2010) (Bengtsson et al., 2009) (Chang et al., 2009) consider the innovation outsourcing process as a whole, (i.e., decision implementation-outcomes). The literature is not limited in the scope of real world scenarios, spanning industry sectors and 
geographies, for example: the investment banking sector is the subject of a real world investigation for outsourcing research by (Grote and Taube, 2007); the outsourcing of R\&D through acquisitions in the pharmaceutical sector is investigated by (Higgins and Rodriguez, 2006), and innovation within the Australian minerals industry is investigated by (Upstill and Hall, 2006). It has been identified, in a study by Fritsch and Gorg (2015), that outsourcing can lead to greater levels of R\&D activities within organisations regardless of their industry. Formal propositions regarding the drivers of innovation outsourcing activities are made and tested by (Calantone and Stanko, 2007). They explore the links between the propensity of a firm to outsource innovation and inventory turnover, profit margin, core competency, employee sales efficiency and learning effects. The exploration of the need for managers to 'give freedom' to suppliers in innovation outsourcing arrangements is addressed by Aubert et al. (2015). Four mechanisms are put forward by Aubert et al. (2015) to resolve the conflicting set of constraints resulting from innovation outsourcing. In their work on IT outsourcing Lee et al. (2004) identify three strategies for outsourcing success: independent; arm's-length; embedded strategies. It is put by Lee et al. (2004) that while the arm's length strategy may bring greater control over costs the embedded approach provides the best opportunity for long term knowledge gain by the outsourcing organisation. Though, a note of caution is offered by Stanko and Olleros (2013) on the potential for knowledge spillage and the commoditisation of ideas. These authors propose several mechanisms that require quantification for outsourcing, are mobility of labour and clustering of firms near the recipient outsourcing firm. The perspective of innovation outsourcing in companies based in emerging economies is the subject of Appiah-Adu (2016), including a discussion of the relative merits of foreign versus local forms as innovation partners; this is also the subject of similar research by Offshoring of R\&D activities is considered by Hinkkanen et al. (2013). The notion of innovation as a competence is put by Waychal et al. (2011). In this work the authors investigate the competences of individual managers involved in outsourcing activities concluding that teams with diverse skill sets are more likely to be active in the success of the venture Waychal et al. (2011). Naghavi, A. and Ottaviano (2008) who conclude that organisations need mechanisms to internalise the R\&D findings made in foreign plants.

From this literature review it was not possible to identify study which consolidates an understanding of innovation outsourcing. Two significant gaps in knowledge relating to innovation outsourcing are identified:

1 Incomplete theory from a management role perspective: Several authors have contributed to the discussion of innovation outsourcing from several perspectives enabling an ongoing building and gradual refinement of theory. However, there is a lack of knowledge relating to the role of management. Individual managerial competence plays a significant role and should be a focus of research (Busi and Mclvor, 2008). 

consequence that innovation outsourcing has for organisations' is one of building capabilities for pursuing an innovation outsourcing agenda. There is a lack of knowledge relating to the practices that an organisation should and should not embrace for pursuing an innovation outsourcing agenda.

The lack of a complete end-to-end innovation outsourcing process that is treated as a firmcentric practice applicable across industries leads to the development of the research detailed in this paper; with the aim of answering the question 'How can firms successfully outsource innovation?', this paper details the development of a framework for innovation outsourcing. From the papers identified in this literature review the following key works are pertinent in relation to their aim to build theory relating to innovation outsourcing: (Nambisan and Sawhney, 2007) who organise the possibilities for externally sourcing innovation along a continuum defined by four variables; (Chesbrough and Crowther, 2006) who identify practices that appear to assist firms adopt open innovation; and (Hoecht and Trott, 2006) who utilise the concepts of trust, collaboration and network to identify the innovation-related risks of strategic outsourcing. Kamuriwo and Baden-Fuller (2016) investigate the outsourcing of core R\&D outlining the roles that proper knowledge and system integration can play in the outsourcing process.

\section{Methodology}

The aim of this research is to develop a generic holistic model to aid firms to successfully outsource innovation. The framework for conducting a systematic review of literature, summarised in Figure 1, is used to inform the methodology used for reviewing the extant literature relating to innovation outsourcing.

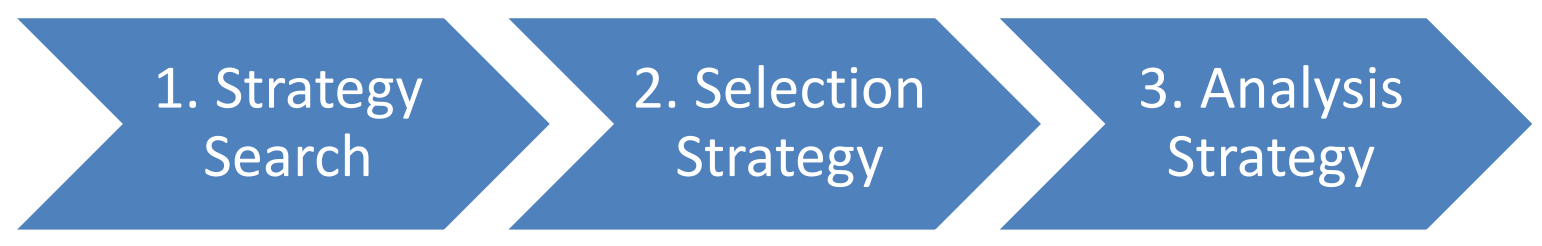

Figure 1: Framework for conducting a systematic review of literature

From Figure 1 the literature review framework is detail thus:

1. Search strategy - involves identifying the literature databases to be used and developing appropriate search terms. The use of specific literature databases are justified based on the domain and their coverage of the domain. Search terms are constructed by aligning them to the study's objectives by identifying the 'intervention', 'population', and 'outcomes of relevance' (Khan et al., 2011a) (Khan et al., 2011b). Alternative spellings and synonyms of search terms, and boolean operators for use within search strings are identified. Key words within papers that are returned are reviewed to verify and refine search strings. 
2. Selection strategy - involves the selection and verification of papers comprising the review. Inclusion and exclusion criteria for papers within the review are explicitly stated. Reviewer bias within the selection procedure is mitigated; typically, by involving a secondary reviewer to confirm that a random sample of selected papers meet the selection criteria specified.

3. Analysis strategy - involves specifying the data extraction, categorisation and analysis procedures that are applied to each paper in the final selection list. These are aligned to the objectives of individual reviews. In general, the analysis undertaken by papers includes: identifying the distribution of papers by year, author, publication and geography; research

Potential techniques for inductively developing the innovation outsourcing framework were reviewed. Template analysis was selected and a template of innovation outsourcing themes was formed from a literature data set of 248 research articles. A framework for successfully outsourcing innovation was the developed from the template by interpreting it as an innovation outsourcing archetype. The framework comprises the process, key practices and factors related to successful innovation outsourcing. The purpose of the proposed framework is to simplify and organise innovation outsourcing phenomena in ways that highlight the outcome of interest, i.e., performance through innovation outsourcing. Development of the framework represents the first two steps of the inductive stage of the descriptive theory-building phase of this study as illustrated in Figure 2.

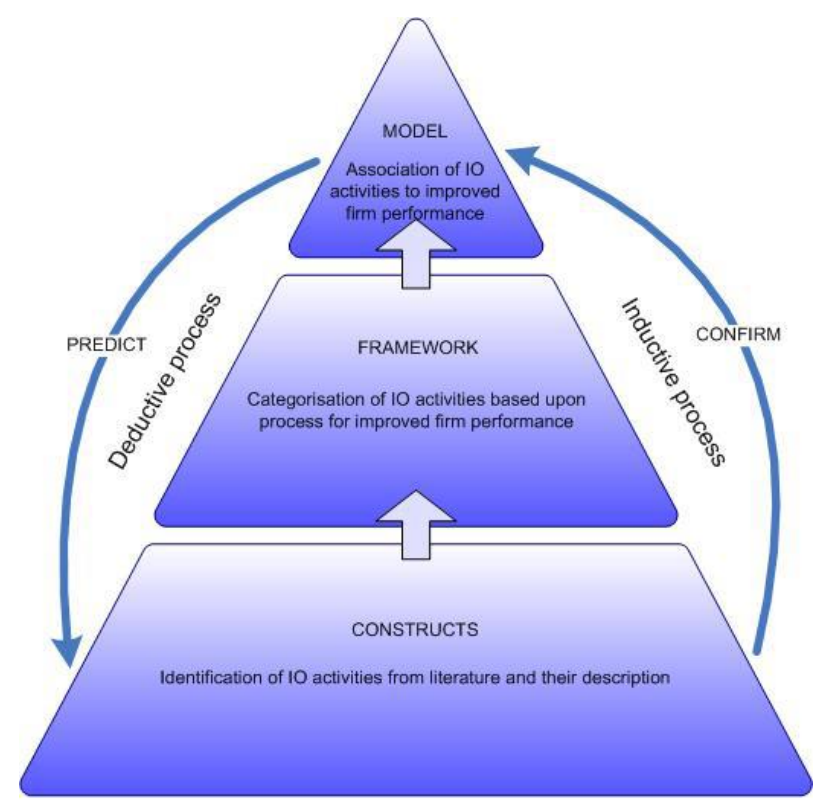

Figure 2: Building the descriptive innovation outsourcing theory 


\subsection{Stage 1: Descriptive Theory Building}

Innovation outsourcing phenomena are elucidated from relevant qualitative data and appropriate labels are ascribed to form categories. The categories are continually reviewed to identify how they relate to performance and how they are best organised to realise performance. The set of categories and their constituent innovation outsourcing phenomena are interpreted as an archetype to form the framework. The framework is the bridge between identifying and describing innovation outsourcing phenomena and exploring the relationships between those phenomena. Innovation outsourcing has been identified as an intrinsically complex real-world phenomenon that has been adopted by firms in various industries worldwide. It comprises many aspects and cuts across multiple disciplines. No studies could be identified in the literature review which addresses innovation outsourcing in its entirety as a firm centric practice applicable across industries.

\subsection{Stage 2: descriptive theory-building - deduction}

The initial stage of this study inductively develops an a'priori model of process and practice relating to the phenomenon of innovation outsourcing. The second, deductive, stage involves testing the model to explore whether the correlations between attributes and outcomes identified in the inductive stage also exist in a different set of data. Theory relating to innovation outsourcing practices and process are confirmed where attributes correlate to outcomes as predicted the theory is confirmed under the observed circumstances. When the attributes of phenomena do not correlate to outcomes as predicted, i.e. anomalies, there arises opportunity to improve theory. The three steps of the inductive stage of the theory building process (i.e. observation, categorisation and definition of relationships) are reviewed to identify whether better definition or categorisation can explain the anomaly. This stage is also illustrated in Figure 2. Pattern matching and explanation building are used to analyse the interview data and explore the correlations between innovation outsourcing activities and process and firm performance. The outcome is an innovation outsourcing model correlating to improved firm performance.

\subsection{Framework development method}

There exist various techniques for inductively developing an a priori innovation outsourcing framework, e.g., analytic induction, grounded theory, framework analysis, etc. The framework analysis and template analysis techniques are outlined below as they form the dominant tools used in the development of the framework for innovation outsourcing.

\subsection{Framework Analysis}

Framework analysis is an inductive approach developed at the UK National Centre for Social Research. It is comprised of five steps: familiarization, identifying a thematic framework, indexing, charting, and mapping and interpretation (Ritchie and Spencer, 1994). Data are categorised to identify a set of main themes and related subtopics which are structured into 
a hierarchical framework. Once a main theme is assessed to be comprehensive it is analysed within a matrix of cases and subtopics. The matrices are then examined for patterns.

\subsection{Template Analysis}

Template analysis (King, 2004) is a process of induction involving the development of an initial template of themes derived from a small section of data. The initial template is then used to analyse the complete data set. As the data set is analysed the template is modified to add, redefine or remove existing themes until the data set is exhausted.

The template analysis technique is summarised in the following steps: Definition of 'a priori themes;

- Reading and familiarisation of the data set.

- Coding and development of template including quality checks.

- Review and interpretation of final template.

Review and interpretation of the final innovation outsourcing template concerns the development of insight from the template. The template itself is not the end product of the analysis, but a tool to produce an interpretation of the data, using its richness to help address the research question. Innovation outsourcing themes are listed to provide an overview and are used to reveal interesting patterns that may warrant attention. The interpretation of themes within the template requires making judgements about the salience of themes that address innovation outsourcing phenomena and the research question.

\subsection{Model Development Method}

The use of influence diagrams is selected as a means to explore and identify the associations between innovation outsourcing activities and firm performance. The rationale for doing so is based on their appropriateness for the specific task. Whilst the syntax of cognitive mapping and influence diagrams may appear to be similar, there are differences between the two techniques relating to the degree of formality and objectivity. As a modelling technique cognitive mapping is used to capture and portray a manager's ideas, beliefs and attitudes with respect to a particular issue and describe how they inter-relate. It is not supposed to be a model of an objective reality; consequently, it can never be shown to be correct or incorrect in an objective sense (Eden et al., 1983). In contrast, influence diagrams offer a greater degree of formality which better aids theory-building. They are able to describe situations both qualitatively and quantitatively by enabling specification of function, relation and scale in both deterministic and probabilistic cases (Howard and Matheson, 2005). They also enable the strict temporal ordering of decisions and events (Goodwin and Wright, 2009). 


\subsubsection{Model Visualisation Method}

Soft systems methodology (SSM) is used for the visualisation of situation perspectives within the framework; SSM is an organised and flexible approach to addressing the complexity of real world situations that require intervention for improvement (Checkland, 2006). SSM addresses the complexity of situations being seen from differing perspectives through the notion of worldviews, i.e., weltanschauung. SSM is not prescriptive; it is flexible providing a set of principles which can be applied to real-world situations where actions can be taken to improve them.

\subsubsection{Model testing -data collection method}

A semi-structured interview technique is employed for the deductive theory-building stage of this study as it is the most appropriate interview technique for addressing the exploratory and explanatory nature of the research question and objectives (Cooper and Schindler, 2008). A key constituent of the interview protocol is an interview research instrument, developed using soft systems methodology (Checkland, 2006), to reflect the inductivelyderived framework as rich pictures.

\section{Model Development and Visualisation}

\subsection{Framework Development}

The purpose of the framework is to simplify and organise innovation outsourcing phenomena in ways that highlight the outcome of interest, i.e., performance through innovation outsourcing. Development of the framework represents the first two steps of the inductive stage of the descriptive theory-building phase of this study. This is illustrated by the two shaded segments of Figure 3. 


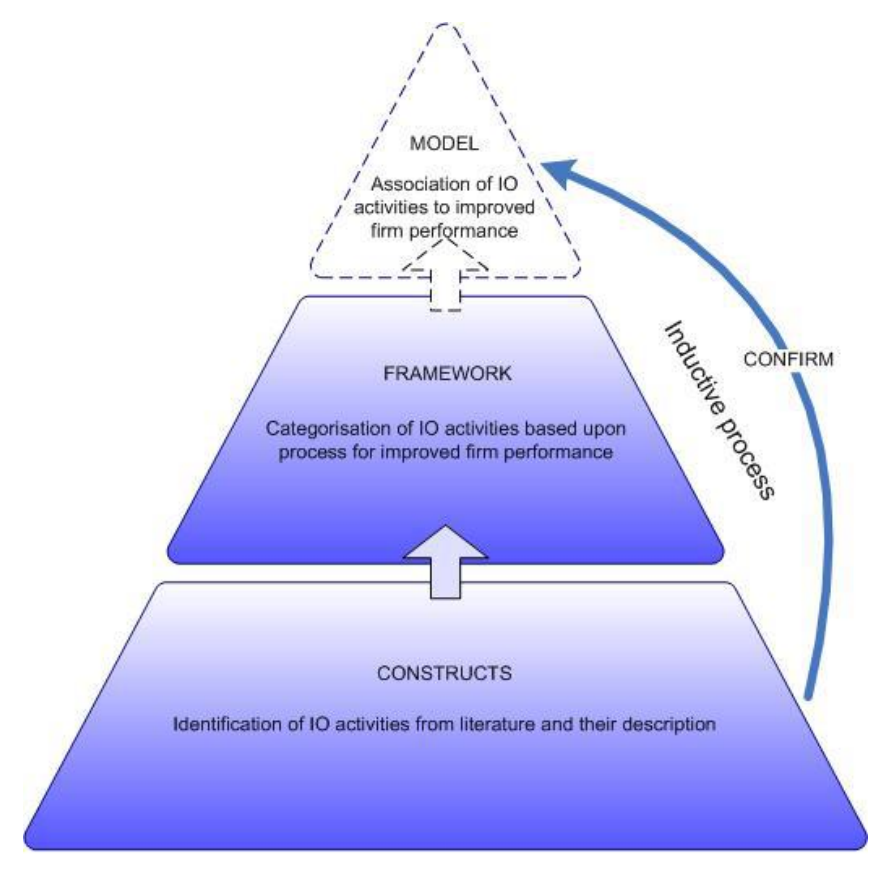

Figure 3. Inductive development of innovation outsourcing framework

Innovation outsourcing phenomena are elucidated from relevant qualitative data and appropriate labels are ascribed to form categories. The categories are continually reviewed to identify how they relate to performance and how they are best organised to realise performance. The set of categories and their constituent innovation outsourcing phenomena are interpreted as an archetype to form the framework. The framework is the bridge between identifying \& describing in-novation outsourcing phenomena and exploring the relationships between those phenomena. The outline model is now discussed in the remainder of this section which displays the results of analysing the literature data set of 248 research articles thematically.

\subsection{The Outline Model}

A preliminary innovation outsourcing model was developed by exploring the framework to identify the associations between capabilities and performance. Influence diagrams are used to illustrate these explorations. Influence diagrams provide a simplified understanding of complex relationships. They are a qualitative graphical representation of dependencies that exist between events and decisions which lead to an outcome given a particular course of action. Nodes are represented as either events or decisions and arrowed arcs between the nodes represent the direction of influence. Influence diagrams have found utility in various disciplines which include medical diagnosis (de Braganca Pereira and Barlow,1990) and manufacturing management (Er and Lezki, 2012). The overall model of innovation outsourcing is developed through statements of correlation between its structure and process (represented further on in this paper as statements p1-p8), and constituent 
capabilities and performance (represented as statements c1-c13). The statements are integral to the model and provide an understanding of the process and capabilities required to successfully outsource innovation and realise performance.

As mentioned before the preliminary model is inductively developed as a set of propositions which relate innovation outsourcing process and capabilities to performance. Its development represents the third step of the inductive stage of the descriptive theory building phase of this research (shown in Figure 3). Its purpose as a preliminary model is to serve as a starting point for validating and improving innovation outsourcing theory relating to the research sub-question. 'What are the capabilities associated with successfully outsourcing innovation, and how should they be organised to realise performance'?

Performance is the outcome of creating value and, ultimately, the rationale for outsourcing innovation. Value creation is achieved through identifying the benefits associated with innovation outsourcing and ensuring that they outweigh the costs involved in its implementation. Firms outsource innovation for the expected benefits. There exist various benefits of innovation outsourcing which are identified within the 'Why particular innovation activity should be outsourced' category of the framework (Amaral et al., 2011) (Bengtsson et al., 2009) (Howells et al., 2008) (Grimpe and Kaiser, 2010) (Piachaud, 2002). Also of interest is the framework for value consideration in outsourcing put forward by Verwaal et al. (2009), additionally the later work by one the same authors explores the need to build relationship capital with foreign outscoring partners (Verwaal, 2017).

Managing the realisation of innovation outsourcing performance is asserted as: $P-P 1$ Performance through innovation outsourcing is managed by ensuring the total utility of benefits outweigh the costs of achieving the delivered benefits.

\subsubsection{The Decision Process}

An overall decision process for improved performance through innovation outsourcing is derived from the innovation outsourcing framework developed in the previous section and is summarised in Figure 4. The association between innovation outsourcing process and performance is asserted as:

P-P2 Performance through innovation outsourcing is dependent on undertaking an ordered set of activities relating to: the determination of innovation activity to be outsourced; the deployment of innovation to be outsourced, and; the management of outsourced innovation. 


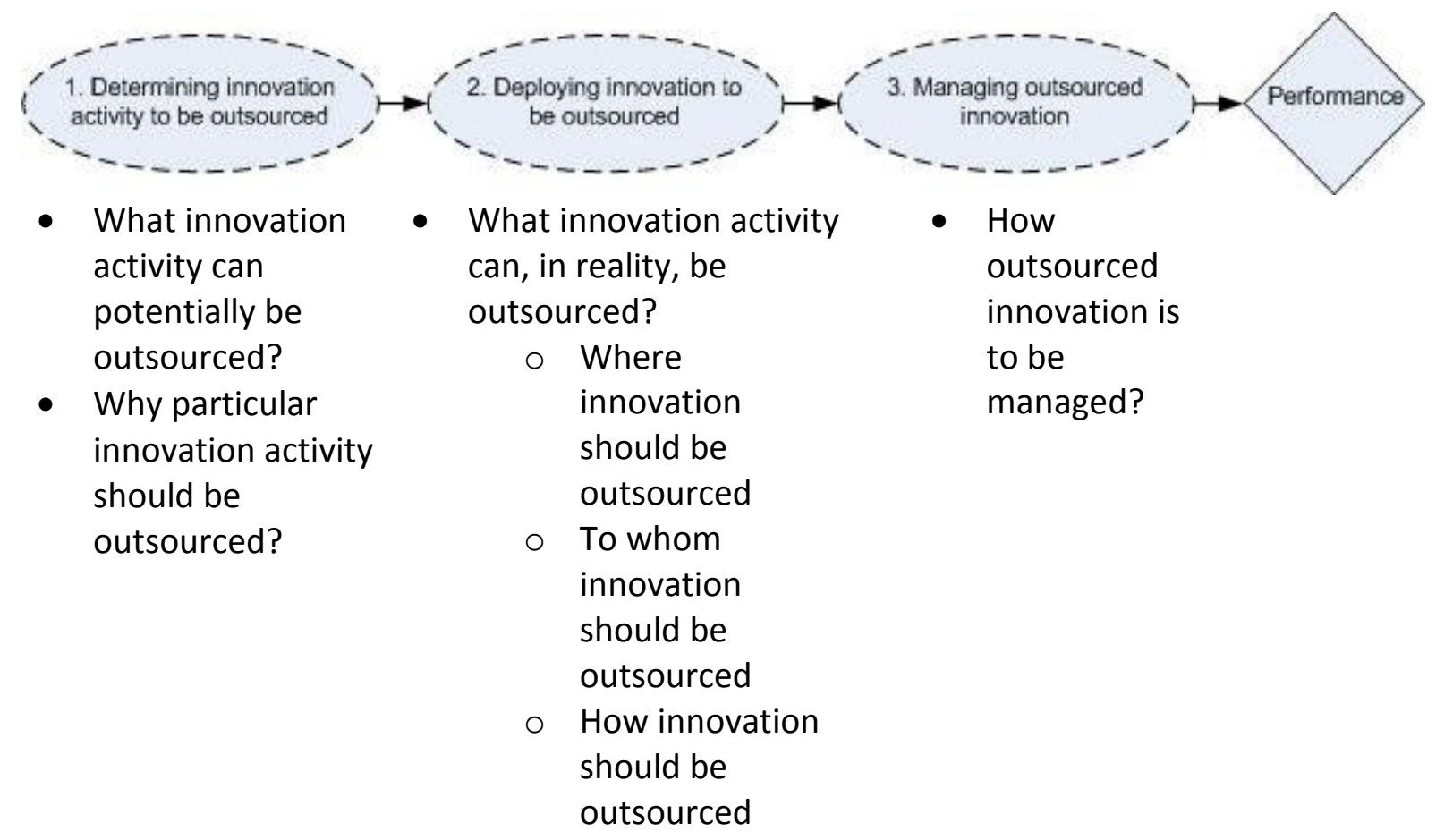

Figure 4: Process overview for outsourcing innovation

\subsubsection{Determining activity to be outsourced}

The process for determining innovation activity to be outsourced is illustrated in Figure 5. It identifies that the innovation activity that can potentially be deployed is dependent on a firm's capability to identify what innovation should be outsourced and why. The association between capability for determining the innovation to be outsourced and performance is asserted as:

P-P3 Performance is dependent on a firm's capability for determining what innovation should be outsourced and why it should be outsourced.

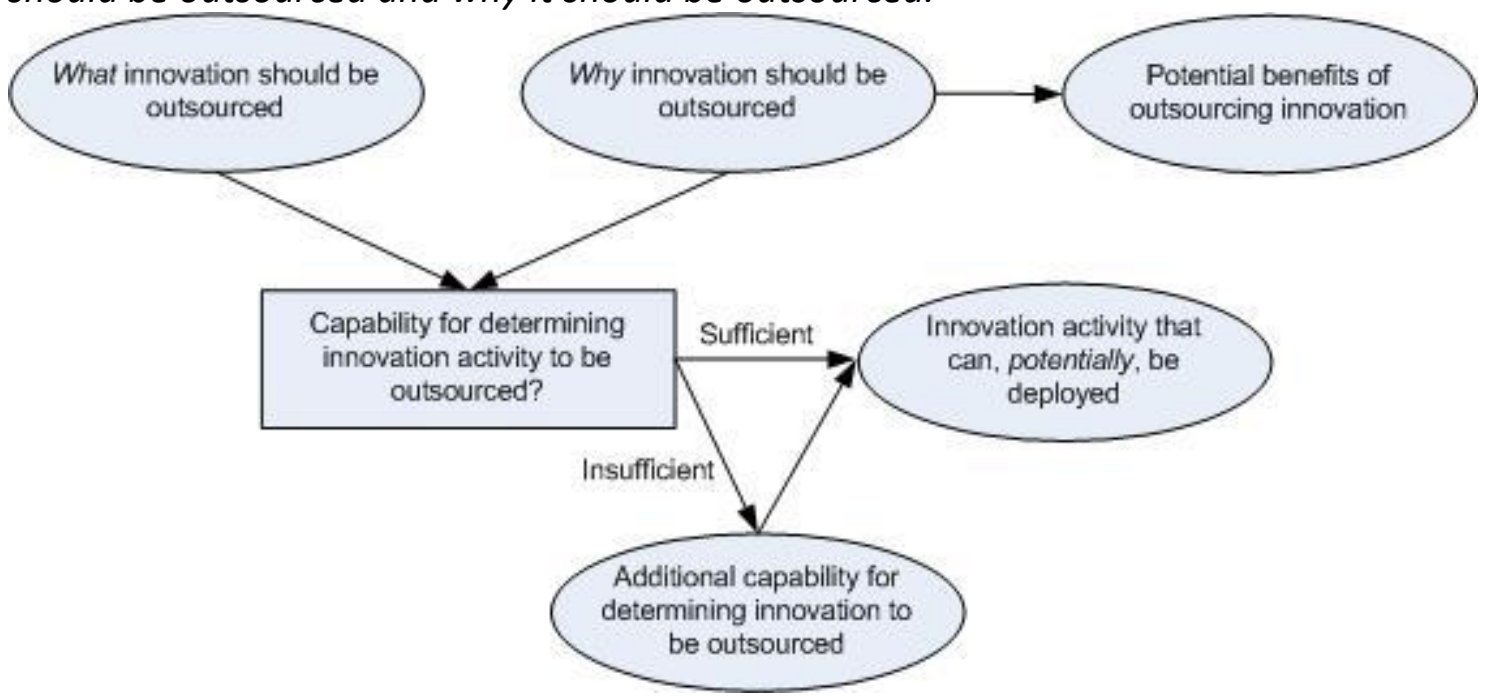

Figure 5: Process for determining innovation activity to be outsourced 


\subsubsection{Deploying innovation to be outsourced}

The process for deploying innovation to be outsourced is illustrated in Figure 6. It identifies that the determination of innovation activity that can, potentially, be outsourced is dependent on a firm's capability for determining where, to whom and how innovation is outsourced. The association between capability for deploying outsourced innovation and performance is asserted as:

P-P4 Performance is dependent on the alignment of deployment capability, (i.e., the determination of where, to whom, and how innovation is outsourced), to the innovation activity being outsourced.

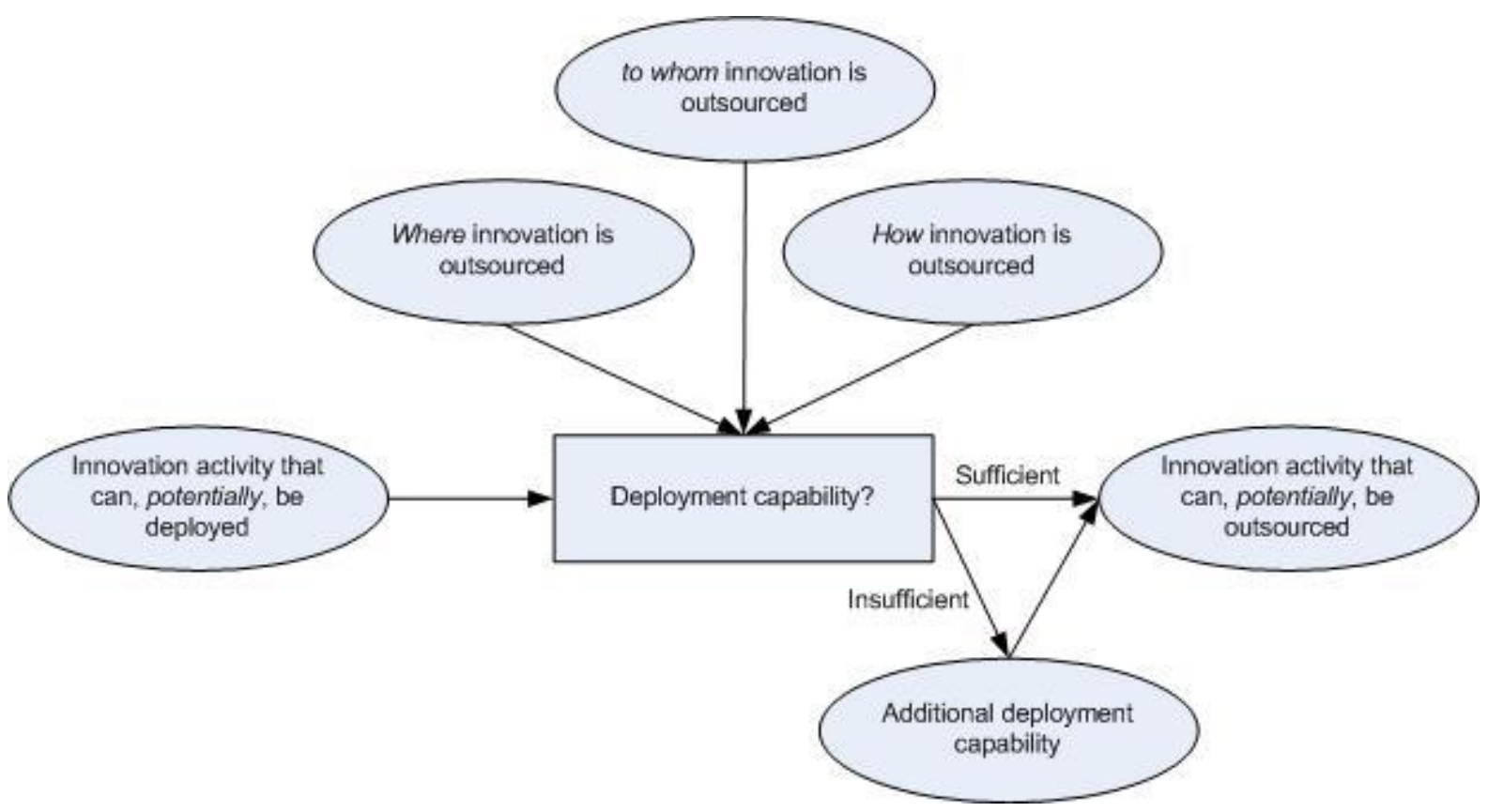

Figure 6: Process for deploying innovation to be outsourced

\subsubsection{Managing outsourced innovation}

The process for managing outsourced innovation is displayed in Figure 7. It identifies that successfully outsourced innovation is dependent on a firm's capability for managing outsourced innovation. Insufficient capability leads to suboptimal performance. 


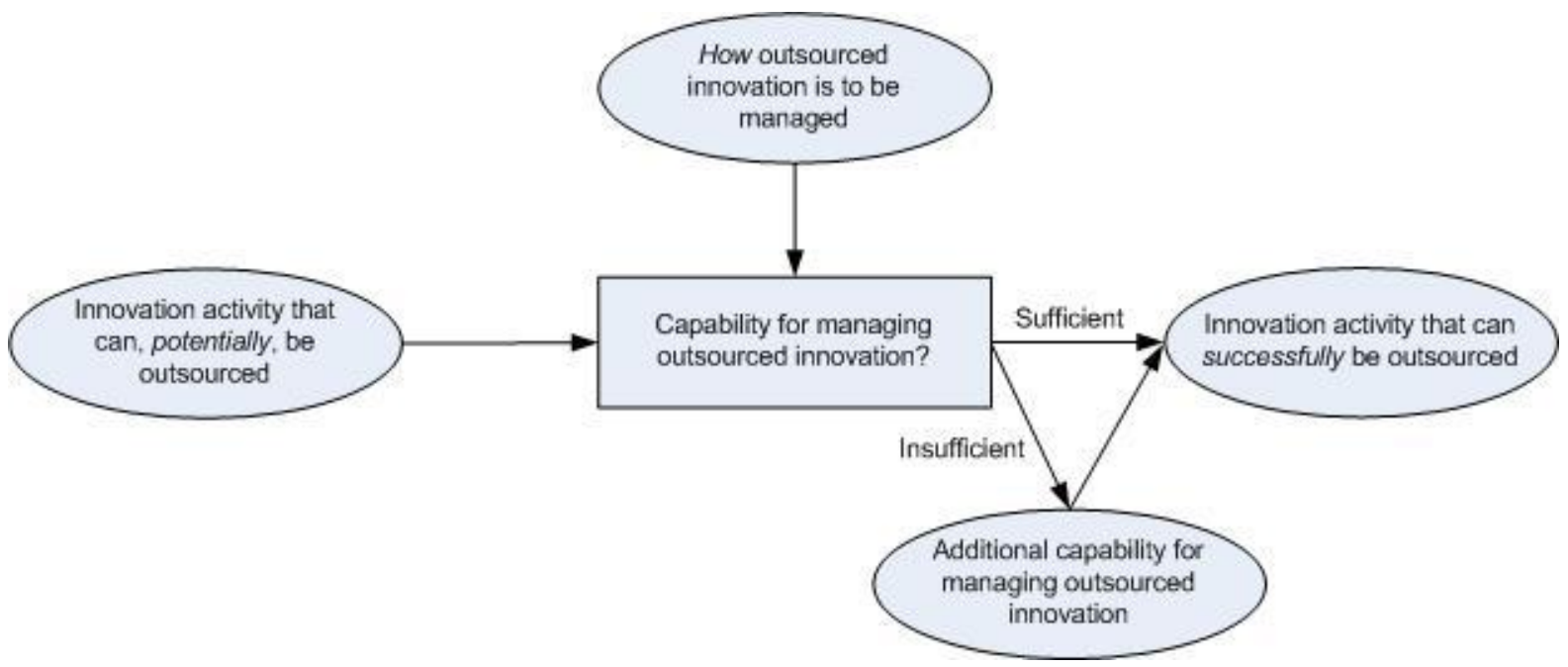

Figure 7: Process for managing outsourced innovation

The association between capability for managing outsourced innovation and performance is asserted as:

P-P5 Performance is dependent on a firm's capability for the day-to-day management of outsourced innovation.

\subsubsection{Capabilities investment and development}

The decision to invest in the development of capabilities for outsourcing innovation is illustrated in Figure 8. It identifies that the decision to outsource is dependent on there being sufficient existing capability to outsource innovation activity; if there is not, the decision to outsource is dependent on the benefits outweighing the additional investment required to enhance innovation outsourcing capability.

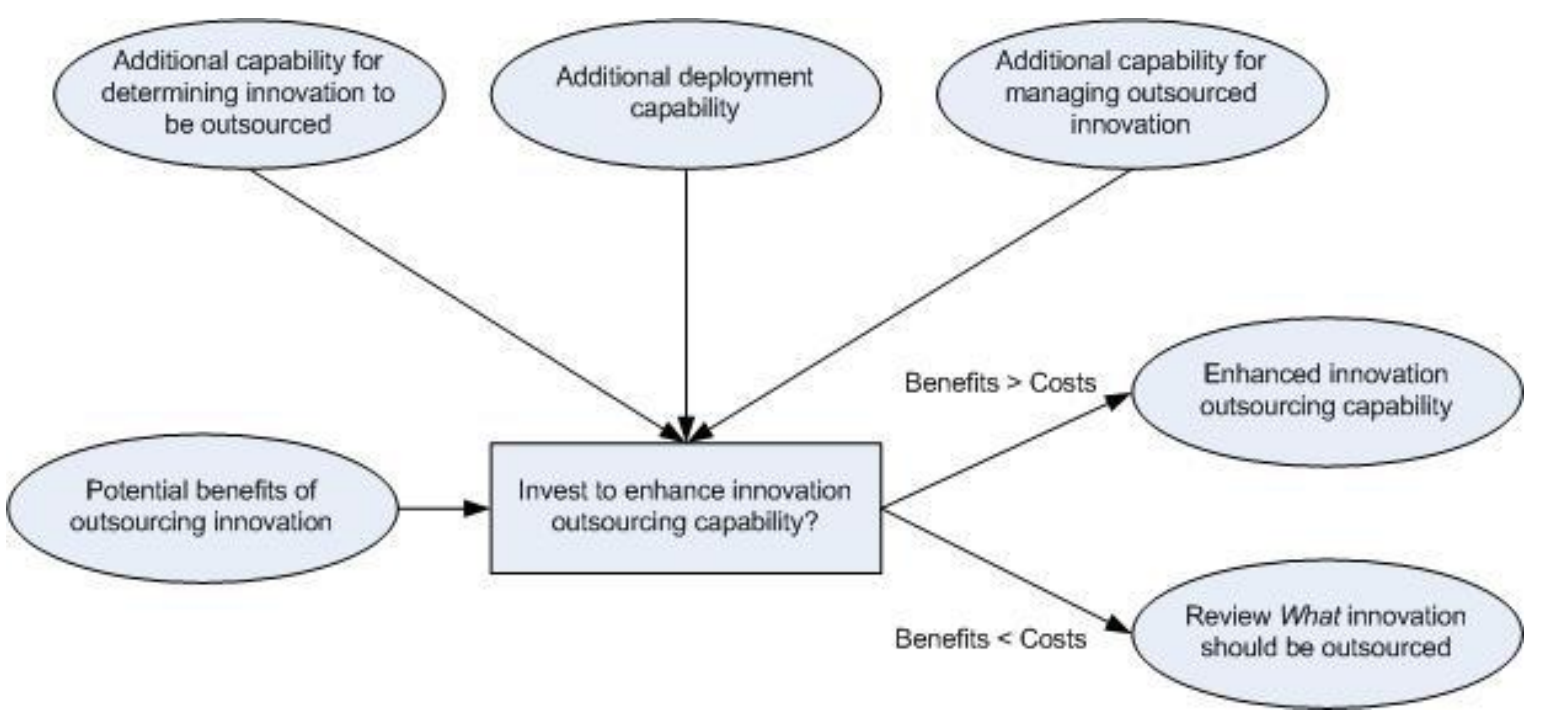

Figure 8: Process for investment decisions 
The broader capabilities of what, why, where, to whom, and how innovation is outsourced and managed day-to-day are further explored to identify specific capabilities and their association with performance. The association between capabilities investment decisions and performance is asserted as:

P-P6 Performance is dependent on appropriate investment decisions to align innovation outsourcing capabilities to the innovation activity being outsourced.

\subsubsection{Portfolio approach}

The process incorporates a portfolio approach to outsourcing innovation. The adoption of a portfolio approach concerns consideration of a firm's innovation activity as a whole. It obliges a firm to review the scope of its innovation activity, define its innovation boundary, and allocate resources accordingly. In general, a portfolio approach offers the following advantages (Cooper et al., 2001):

- $\quad$ Strategic alignment -ensuring innovation outsourcing efforts match the needs of the firm's overall strategy.

- Maximising value -ensuring the highest returns relative to investment.

- $\quad$ Balance -managing risk versus reward based on particular characteristics, (e.g., type of innovation -incremental/radical).

The association between a portfolio approach and performance is asserted as:

P-P7 A portfolio approach to outsourcing innovation is positively associated with performance.

\subsection{Capabilities}

The model encompasses a dynamic capabilities approach to outsourcing innovation. Dynamic capabilities are a "firm's ability to integrate, build, and reconfigure internal and external competencies to address rapidly changing environments"(Teece et al., 1997). There is emphasis on the development of management capabilities and difficult-to-imitate combinations of organisational, functional and technological skills (Mclvor, 2005). The association between dynamic capabilities and performance is asserted as:

P-P8 The continual identification, resourcing and development of capabilities aligned to the innovation activity being outsourced is positively associated with sustained performance.

What activity can potentially be outsourced? The specific capabilities associated with the broader capability of what innovation activity can potentially be outsourced are illustrated in Table 2. 
Table 2: Influences on what activity can potentially be outsourced

\begin{tabular}{|c|c|}
\hline Innovation Activity & Influences \\
\hline What innovation should be outsourced & $\begin{array}{l}\text { Stage of development } \\
\text { Differentiation of core and non-core } \\
\text { innovation activity }\end{array}$ \\
\hline
\end{tabular}

Differentiation of core and non-core innovation activity: This concerns a firm's ability to differentiate its innovation activity according to the extent to which it is related to the core capabilities of the firm. The theoretical underpinning of this is the notion of core competencies, i.e., protecting those competencies in which a firm outperforms its competitors and which are at the core of its strategic position (Hamel and Prahalad, 1994). This is asserted as:

P-C1 Performance is dependent on the effectiveness with which innovation activities associated with core capabilities are differentiated from those associated with non-core capabilities.

Innovation can be outsourced anywhere along the outsourcing continuum, from raw ideas to market-ready ideas to market-ready products. There is also a balance of risk, reach, speed and cost attributes that are determined from a company's internal and external (i.e., industry/market) factors (Nambisan and Sawhney, 2007). The capability to effectively determine the optimal stage along the outsourcing continuum at which a particular innovation is outsourced provides improved firm performance through resource optimisation. This is asserted as:

P-C2 Performance is dependent on the effective determination of the optimal stage along the innovation continuum at which a particular innovation is outsourced.

\subsubsection{Why a particular activity should be outsourced}

The clarity of rationale for outsourcing specific innovation activity refers to the reason why particular innovation activity is under consideration for being outsourced. It is from this that the perceived benefits, (i.e., what the firm expects by outsourcing the innovation activity), are derived. The theoretical basis behind a firm's rationale is the concept of utility. Utility theory asserts that products or services are not procured for their own sake, but for their expected benefits (Lancaster, 1971). Utility of innovation outsourcing is expressed as either improving potential profits or reducing innovation costs. This is asserted as:

P-C3 Performance is dependent on a firm's ability to determine clear and unambiguous rationales for outsourcing specific innovation activity. 


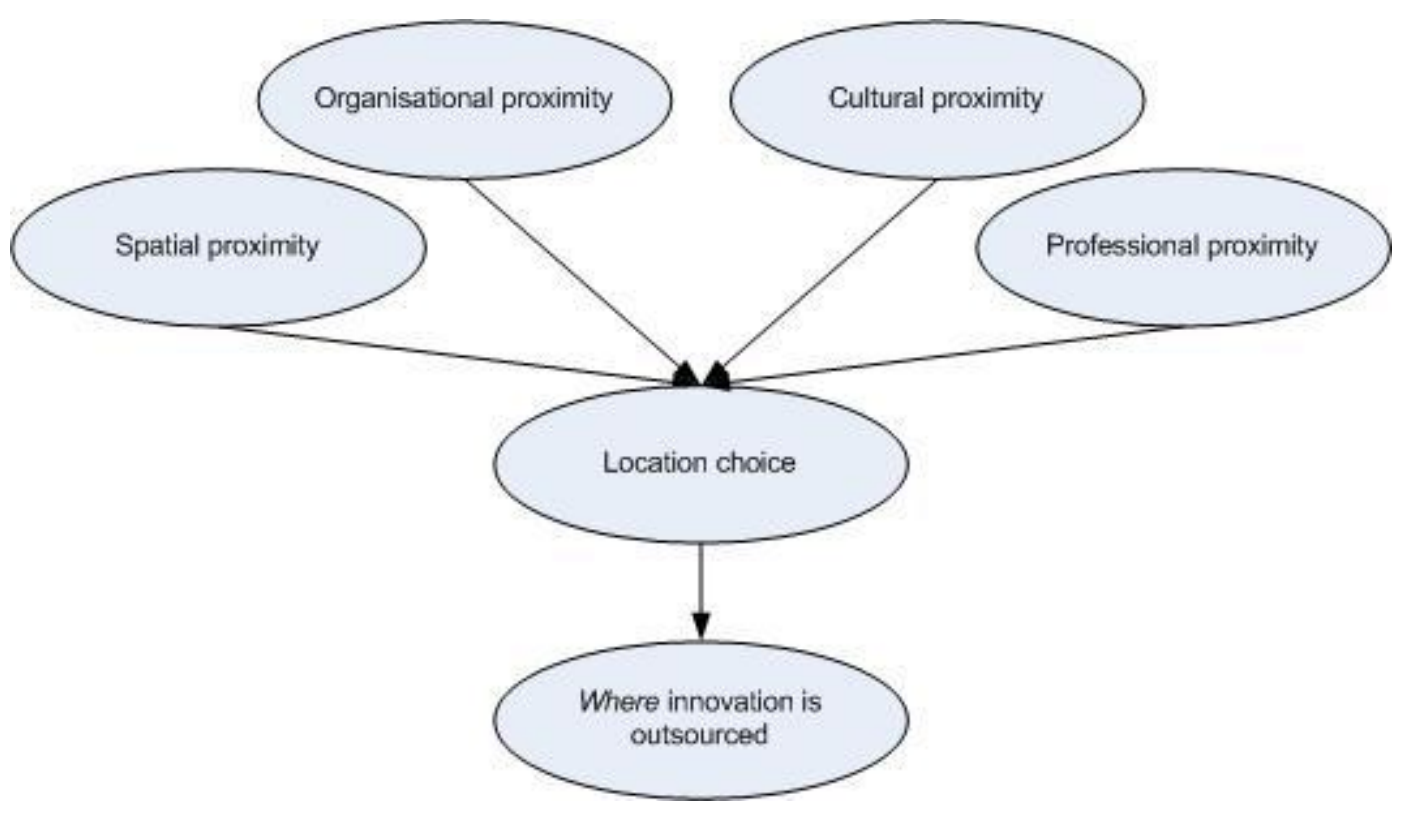

Figure 9: Influences on where innovation activity should be outsourced

\subsubsection{Where innovation should be outsourced to}

The specific capability associated with the broader capability of where innovation activity should be outsourced is illustrated in Figure 9. A firm's choice for outsourcing innovation is typically based on the potential benefits of the location. For example, Western economy firms may outsource innovation activity to developing economies to take advantage of lower innovation development costs. Similarly, firms based in developing economies may outsource innovation to Western economies to gain access to technologies for improved profit margins. The closer the proximity of the outsourced location to the firm the simpler it is to integrate external knowledge and realise the potential of improved firm performance. This is asserted as:

P-C4 Performance is dependent on a firm's ability to determine the level of various proximities, (i.e., spatial, organisational, cultural, and professional), associated with supplier/partner location.

Table 3: Influences on to whom innovation activity should be outsourced

\begin{tabular}{|c|l|}
\hline Innovation Activity & Influences \\
\hline To whom innovation activity is outsourced & \begin{tabular}{c|} 
- Mode of outsourcing \\
- Pool of potential providers
\end{tabular} \\
& - Multi-criteria selection framework \\
& - Length of relationship \\
\hline
\end{tabular}

The specific capabilities associated with determining to whom innovation activity should be outsourced are illustrated in Table 3. Determining mode of outsourcing: Modes of 
outsourcing refer to the type of relationship used by a firm for outsourcing its innovation. Examples include: alliances, R\&D contracts and technology licensing. This is asserted as:

P-C5 Performance is dependent on the ability to align the mode of the outsourced activity.

Differing outsourcing needs require different types of innovation outsourcing partner. For example, outsourced innovation for raw ideas requires a different type of partner to outsourced innovation for market-ready products. This is asserted as:

P-C6 Performance is moderated by the ability to develop and maintain a large and diverse pool of potential innovation outsourcing partners/providers.

Selecting partners from a large number of possible suppliers with various levels of capability and different potentials is a complex multi-criteria decision-making problem with both qualitative and quantitative factors. A comprehensive framework for selecting the most suitable innovation outsourcing partner is essential to ensuring the objectives of innovation outsourcing are achieved. This is asserted as:

P-C7 Performance is moderated by the ability to develop and use a comprehensive multicriteria decision-making framework for selecting the most suitable innovation outsourcing partner/provider.

Determining the optimal lifespan of an innovation outsourcing relationship is essential to its performance. The relationship between innovation outsourcing age and performance is $U$ shaped; performance initially declines, reaches a low point and then improves again. Management inclinations to terminate relationships early must be suppressed. This is asserted as:

P-C8 Performance is moderated by the ability to determine the optimal lifespan of an innovation outsourcing relationship.

\subsubsection{How innovation should be outsourced}

The specific capabilities associated with determining to whom innovation activity should be outsourced are illustrated in Table 4.

Greater modularity of products and services, knowledge and organisational design is necessary to enable effective innovation outsourcing. Complex systems, however, are not completely decomposable and firms should not seek to design perfectly modular systems for fear of losing meaning and control over the outsourced activity. This is asserted as:

P-C9a Performance is moderated by the ability to determine the appropriate level of product/service architecture modularity. 
P-C9b Performance is moderated by the ability to determine the appropriate level of knowledge architecture modularity.

P-C9c Performance is moderated by the ability to determine the appropriate level of organisational design modularity.

P-C9d Performance is dependent by the ability to align product/service, knowledge, and organisational modularity for the outsourced innovation activity.

Table 4: Influences on to how innovation activity is outsourced

\begin{tabular}{|l|l|}
\hline Innovation Activity & Influences \\
\hline To how innovation activity is outsourced & $\begin{array}{l}\text { - Modularity } \\
\text { - Flexibility }\end{array}$ \\
& $\begin{array}{l}\text { - Governance and control } \\
\text { - Organisational culture }\end{array}$ \\
\hline
\end{tabular}

Increased firm flexibility enables the realisation of improved performance through innovation outsourcing. Information technology, (IT), usage within innovation outsourcing enhances firm flexibility by reducing communication and transaction costs. Finance procedures appropriate to innovation outsourcing enhances firm flexibility by addressing the associated risks of uncertainty. This is asserted as:

P-C10a Performance is dependent on the flexibility of information technology structures.

P-C10b Performance is dependent on the flexibility of firm finance procedures.

P-C10c Performance is dependent on the flexibility of innovation employment intensity.

The role of governance and control within innovation outsourcing relationships is to protect a firms' intellectual property, (IP), whilst ensuring that innovation objectives are realised without inhibition. This requires a balance of formal, (i.e., contractual), and informal, (i.e., non-legal), mechanisms appropriate to the nature of the innovation being outsourced. This is asserted as:

P-C11a Performance is dependent on the ability to develop and use formal governance and control when outsourcing innovation.

P-C11b Performance is dependent on the ability to develop and use informal governance and control when outsourcing innovation.

P-C11c Performance is dependent on an appropriate balance of formal and informal governance and control for the innovation activity being outsourced. 
An effective organisational culture for innovation outsourcing differs to that of traditional innovation, furthermore differing outsourced innovation activity requires different subcultures. The lack of an appropriate innovation outsourcing subculture constrains the absorptive capacity of the firm, (i.e. the ability to integrate effectively innovation knowledge acquired from outside the firms' boundaries), and consequently innovation outsourcing performance. This is asserted as:

P-C12 Performance through improved absorptive capacity is dependent on the development and nurturing of subcultures appropriate to the innovation activity outsourced.

\subsubsection{How outsourced innovation is to be managed}

The specific capabilities associated with determining how outsourced innovation is to be managed are illustrated in Table 5.

Table 5: Influences on how innovation activity is outsourced

\begin{tabular}{|l|l|}
\hline Innovation Activity & Influences \\
\hline How outsourced innovation activity is to be & $\begin{array}{l}\text { Project management } \\
\text { managed }\end{array}$ \\
& - Knowledge management \\
& - Learning management \\
\hline
\end{tabular}

Determining day-to-day management of outsourced innovation: This concerns the spanning of firm boundaries when outsourcing innovation, and is asserted as:

P-C13a Performance is moderated by the ability to manage innovation outsourcing through projects.

P-C13b Performance is dependent on the ability to understand what constitutes knowledge and controls its flow across boundaries.

P-C13c Performance is dependent on the ability to learn by combining new architectural and component knowledge with prior knowledge.

\subsection{The preliminary model}

The preliminary innovation outsourcing model has been developed through exploration of the innovation outsourcing framework detailed in this section. Exploration of the framework involves the identification of two types of association between innovation outsourcing phenomena and performance. These are, firstly, the relationships between the ordering and organisation of innovation outsourcing capabilities and performance, i.e., process, and; secondly, the relationships between the attributes of innovation outsourcing capabilities and performance. The model comprises a set of propositions relating aspects of innovation 
outsourcing to performance. The preliminary model is inductively developed as a set of propositions which relate innovation outsourcing process and capabilities to performance. Its purpose as a preliminary model is to serve as a starting point for validating and improving innovation outsourcing theory relating to the research sub-question 'What are the capabilities associated with successfully outsourcing innovation, and how should they be organised to realise performance'? The following section of this paper details the validation of the preliminary innovation outsourcing model.

\section{Validation}

As a pre validation stage a survey was conducted. The purpose of the survey was to gather primary data for deductively testing the preliminary generic holistic innovation outsourcing model that was inductively formulated (detailed in the previous section). The preliminary model has been synthesised from a large and disparate literature data set. It is described as propositions which correlate the overall innovation outsourcing process and constituent capabilities to firm performance. Interviews were conducted with eight senior executives and professionals with a combined total of over 150 years' experience in innovation outsourcing. Their experience related to numerous organisations in several industry sectors. The firms ranged in size from SMEs, with a turnover of less than $\$ 20 \mathrm{~m}$ to global conglomerates.

\subsection{Overview of the Data Analysis}

The interview data has been compared with the propositions through a process of patternmatching and explanation building to validate propositions and explain anomalies. A validated overall innovation outsourcing model addresses the aim of this research to develop a generic holistic approach by which firms can successfully outsource innovation (shown in Figure 9). The prepared interview data is used to test the preliminary holistic innovation outsourcing model. This is undertaken by exploring whether the data confirms or contrasts with the correlations between innovation outsourcing attributes and firm performance outcomes (i.e., process and capability propositions, $p-p 1$ to $p$-p8 and $p$-c1 to $p$ c13c). 


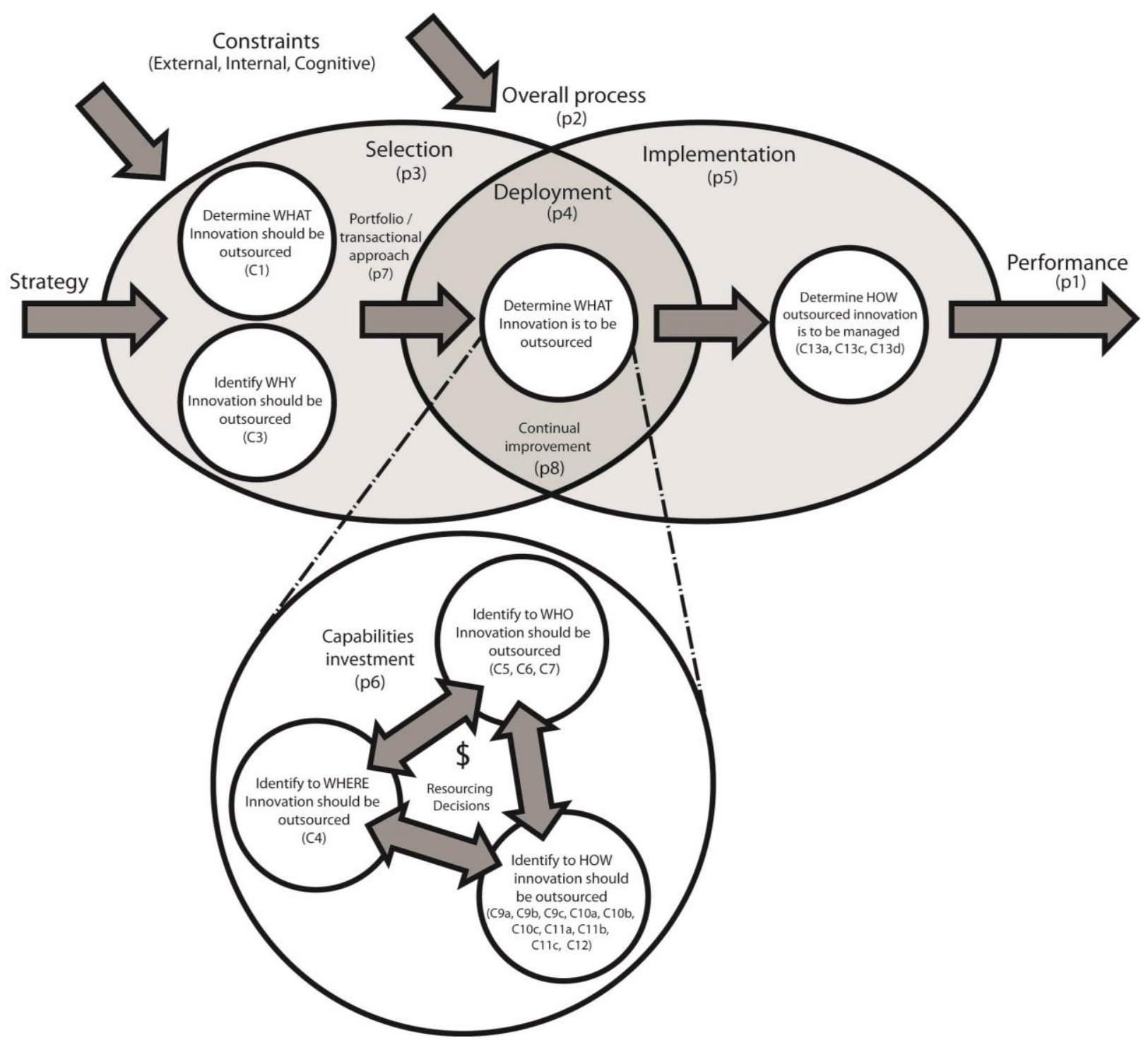

Figure 10: Overall innovation outsourcing model

\subsection{Discussion of the findings}

Interview survey data has been analysed and used to deductively test the process and capabilities propositions which form a preliminary generic holistic innovation outsourcing model. A process of pattern-matching and explanation building is used to validate the propositions and explain anomalies. The outcome is a validated generic holistic model for outsourcing innovation to address this study's primary research question, 'how can firms successfully outsource innovation?'. The overall innovation outsourcing process model and its associated capabilities are illustrated as Figure 10. The model, (illustrated in Figure 10), is represented as a three stage process involving, the determination of innovation activity to be outsourced, (i.e., selection), the deployment of innovation to be outsourced, (i.e., deployment) and the management of outsourced innovation, (i.e., implementation). 


\subsubsection{Process}

\section{p1. Performance}

Support for the realisation of performance through the model's process was identified during the process walkthrough and interviews. Firms do not, however, have an explicit focus on measuring either the total utility of benefits nor the costs of achieving delivered benefits. In summary, proposition p1, (i.e., 'performance through innovation outsourcing is managed by ensuring the total utility of benefits outweigh the costs of achieving the delivered benefits'), is not confirmed by existing practice, but does find support amongst interviewees. Survey results support existing knowledge which identifies that firms focus on perceived expectations, rather than actual outcomes (Hsuan and Mahnke, 2011).

\section{p2. Overall process}

Innovation outsourcing is a three stage process involving, the determination of innovation activity to be outsourced, (i.e., selection); the deployment of innovation to be outsourced, (i.e., deployment), and; the management of outsourced innovation, (i.e., implementation). Survey results contrast with existing knowledge which views the innovation outsourcing process simplistically as two discrete and independent steps of selection and implementation (Cui and Loch, 2011).

\section{p3. Selection}

The selection of innovation to be outsourced involves determining what innovation should be outsourced and why it should be outsourced. Whilst selection can be initiated by determining either what innovation should be outsourced or why innovation should be outsourced, one must be aligned to the other. Survey results add to existing knowledge by identifying that the selection of innovation activity can be initiated with the determination of either the innovation activity to be outsourced or the rationale for outsourcing, but that they must be aligned.

\section{p4. Deployment}

The deployment of outsourced innovation involves the alignment of a firm's innovation outsourcing capability, (i.e., the determination of where, to whom, and how innovation is outsourced), with the innovation activity to be outsourced. Survey results contrast with existing knowledge (Cui and Loch, 2011) by identifying an intermediate stage, (i.e., deployment), between the selection and implementation of outsourced innovation to ensure sufficient organisational capability and capacity for outsourcing. 


\section{p5. Implementation}

The implementation of outsourced innovation involves the day-to-day management of outsourced innovation. Survey results support existing knowledge which displays the need for effective management of outsourced innovation (Cui and Loch, 2011).

p6. Capabilities investment

Appropriate investment decisions to align innovation outsourcing capabilities to the innovation activity being outsourced is positively associated with innovation outsourcing performance.

Survey results add to existing knowledge by displaying the need to consider and, if appropriate, invest in innovation outsourcing capabilities to aid performance. This research has identified that sufficient consideration and investment in innovation outsourcing capabilities aids performance. Survey results support existing knowledge by displaying that insufficient consideration and investment in innovation outsourcing capabilities moderate performance due to increased risk (Piachaud, 2002).

\section{p7. Portfolio/transactional approach}

A portfolio or transactional approach may be adopted for outsourcing innovation. Survey results add to existing knowledge by displaying that either a portfolio or transactional approach can be adopted for outsourcing innovation. The adoption of a portfolio approach is consistent with initiating selection by determining what innovation activity is to be outsourced. The adoption of a transactional approach is consistent with initiating selection by determining why innovation activity should be outsourced.

p8. Continual improvement

Survey results add to existing knowledge by displaying that innovation outsourcing involves undertaking deliberate interventions to existing organisational routines and procedures. Interventions are undertaken to ensure capabilities are appropriate and sufficient for the innovation activity being outsourced.

\subsubsection{Capabilities}

Findings concerning the capabilities associated with the innovation outsourcing process are summarised and discussed below.

c1. Differentiating core and non-core activity

Survey results support existing knowledge which identifies that firms have a clear focus on their core innovation activity which they differentiate from their non-core activity (Festel et al., 2011). 


\section{c3. Clarity of rationale}

Expected performance through innovation outsourcing is dependent on a firm's ability to determine clear and unambiguous rationales for outsourcing specific innovation activity. Survey results support existing knowledge which displays that firms identify a clear rationale for outsourcing innovation (Howells et al., 2008) (Grimpe and Kaiser, 2010). Results also display that firms clearly differentiate between a 'cost reduction' rationale and other rationales which ultimately improve profits (Bengtsson et al., 2009).

\section{c4. Location choice}

Expected performance through innovation outsourcing is dependent on a firm's ability to determine the level of various proximities, (i.e., spatial, organisational, cultural, and professional), associated with supplier/partner location. Survey results support existing knowledge which identifies that capability for managing supplier/partner locations is more than the ability to identify and manage geographical distance. It also involves the ability to identify and manage 'psychic' distance, (i.e., language, culture and business practices) (Martinez-Noya et al., 2012).

\section{c5. Mode of outsourcing}

Expected performance through innovation outsourcing is dependent on the ability to align the mode of outsourced innovation to a firm's strategic needs. Survey results support existing knowledge which identifies that the choice of innovation outsourcing mode should be aligned to the strategic needs of a firm (Baloh et al., 2008).

\section{c6. Pool of providers}

Expected performance through innovation outsourcing is moderated by the ability to develop and maintain a large and diverse pool of potential innovation outsourcing partners/providers.

Survey results add to existing knowledge by displaying that a lack of appropriate and available innovation outsourcing partners/providers results in lost innovation opportunity, and consequently, lower performance.

\section{c7. Provider selection}

Expected performance through innovation outsourcing is moderated by the ability to develop and use a comprehensive multi-criteria decision-making framework for selecting the most suitable innovation outsourcing partner/provider. Survey results support existing knowledge which identifies the need to use a broad and balanced range of criteria, both formal and informal, for selecting appropriate partners/providers. Formal selection criteria emphasised the protection of intellectual property (Wu et al., 2013), and finance. Informal criteria, (e.g., trust), were used to build strong relationships (Ford et al., 2012). 
c9a, c9c, c9d. Degree and alignment of modularity

Survey results support existing knowledge which displays the need for appropriate levels of product/service architecture and organisational design modularity that are aligned to the innovation activity being outsourced (Grote and Taube, 2007).

c10a to c10c. Degree of flexibility

Expected performance through innovation outsourcing is dependent on the flexibility of: information technology structures; firm finance procedures, and; innovation employment intensity. Survey results both support and add to existing knowledge concerning c10a, c10b, and c10c.

IT flexibility (c10a): Survey results support existing knowledge which displays that the efficiency and effectiveness of innovation outsourcing is aided by flexible firm structures and procedures relating to information technology (Massini and Miozzo, 2012). finance flexibility (c10b): Survey results support existing knowledge which displays that the efficiency and effectiveness of innovation outsourcing is aided by flexible firm structures and procedures relating to finance (Hempell and Zwick, 2008).

employee flexibility (c10c): Survey results support existing knowledge which displays that the efficiency and effectiveness of innovation outsourcing is aided by flexible firm structures and procedures relating to employee intensity (Wouters, 2010).

\section{c11a to c11c. Governance and control}

Expected performance through innovation outsourcing is dependent on the ability to develop and balance formal and informal governance and control when outsourcing innovation. Survey results support existing knowledge which displays the need to develop and use a balance of both formal and informal governance and control routines and procedures when outsourcing innovation (Roy and Sivakumar, 2012). Firms cited trust, and peripheral knowledge (Tiwana and Keil, 2007) as particular examples of informal control used.

\section{c12. Organisational culture}

Expected performance through innovation outsourcing is dependent on the development and nurturing of subcultures appropriate to the innovation activity being outsourced. Survey results support existing knowledge. Firms understand that successful innovation outsourcing requires organisational subcultures different to that for developing innovations internally (Mortara et al., 2010).

c13a to c13c. Day-to-day management

Expected performance through innovation outsourcing is: moderated by the ability to manage innovation outsourcing through projects; dependent on the ability to understand what constitutes knowledge and control its flow across boundaries; dependent on the ability to learn by combining new architectural and component knowledge with prior 
knowledge. Survey results both support and add to existing knowledge concerning c13a, $\mathrm{c} 13 \mathrm{~b}$, and $\mathrm{c} 13 \mathrm{c}$.

Managing through projects (c13a):

Survey results support existing knowledge concerning the use of project management skills specific to technology development with external partners/providers to support innovation outsourcing. They also support the need for a broad range of skills necessary for successfully managing outsourced innovation projects, i.e., resource management, understanding strategic value, customer insight, technological and organisational skills; managing R\&D culture, communication and cooperation, and social responsibility (Flipse et al., 2013).

Managing knowledge (c13b):

Knowledge associated with innovation products/services is not completely decomposable (Paoli and Prencipe, 1999). Consequently, there is a risk of firms, inadvertently, transferring proprietary knowledge to suppliers in outsourcing relationships. Survey results add to existing knowledge by identifying the high cost of innovation outsourcing relationships especially in managerial time and energy. There is a need to ensure sufficient flow of information between a firm and their partners/providers so that innovation outsourcing objectives are met. A firm within the survey addressed this issue by ensuring experienced managers always accompanied less-experienced employees when meeting with outsourced innovation suppliers.

Managing learning (c13c):

Survey results support existing knowledge which identifies the need for a focus on absorptive capacity (Lowman et al., 2012). They also support the need to ensure that the outcomes of outsourced innovation activity are efficiently disseminated and effectively integrated in to the firm's existing knowledge base (Zirpoli and Becker, 2011a). Survey results display a particular emphasis on the need to disseminate tacit knowledge to promote effective learning (Ford et al., 2012).

\section{Discussion}

The validated generic holistic model developed by this study consolidates current understanding of innovation outsourcing and extends it, specifically, regarding the role of management. In particular, this study adds to existing knowledge in relation to: systems, utility and value, and the integration of strategic management perspectives within an overall innovation outsourcing process. This research's contributions to innovation outsourcing management theory relate to process. They are summarised in Table 6, and displayed within the model. 
Table 6: Innovation outsourcing process capabilities

\begin{tabular}{|c|l|}
\hline \multicolumn{2}{|c|}{ INNOVATION OUTSOURCING PROCESS CAPABILITY } \\
\hline \multirow{2}{*}{ PROCESS } & p1. Performance outcome \\
\cline { 2 - 3 } & p2. Overall process for outsourcing innovation \\
\hline \multirow{2}{*}{ SELECTION } & P3. Selection stage \\
\cline { 2 - 2 } & P7. Portfolio/transactional approach \\
\hline \multirow{2}{*}{ DEPLOYMENT } & P4. Deployment stage \\
\cline { 2 - 2 } & P6. Capabilities investment \\
\cline { 2 - 2 } & P8. Continual improvement \\
\hline IMPLEMENTATION & P5. Implementation stage \\
\hline
\end{tabular}

A capabilities framework for managing innovation outsourcing is developed by this study to address a key gap in knowledge identified from the review of literature. It is presented below as Table 7. The capabilities framework comprises a set of specific capabilities, (c1c13), associated with innovation outsourcing performance which are structured according to their role, (i.e., what, why, where, to whom, and how innovation is outsourced and managed day-to-day), within the three stages of the innovation outsourcing process, (i.e., selection, deployment, and implementation). Each capability and its corresponding role is the outcome of validation through the analysis of survey data. The framework has been developed using a systems-led contingency approach, and is presented as a portfolio of capabilities. It reflects that there is no one best way to manage innovation outsourcing and that managerial decisions for effective firm performance are dependent on the nature of the environment in which the organisation operates. The framework comprises a more comprehensive set of capabilities with greater breadth across the innovation outsourcing process than exists within the extant literature, for example, (Zirpoli and Becker, 2011a).

Table 7: Innovation outsourcing capabilities

\begin{tabular}{|c|c|c|}
\hline \multicolumn{3}{|c|}{ INNOVATION OUTSOURCING CAPABILITY } \\
\hline \multirow[t]{2}{*}{ SELECTION } & WHAT & C1. Differentiating core and non-core activity \\
\hline & WHY & C3. Clarity of rationale \\
\hline \multirow[t]{12}{*}{ DEPLOYMENT } & WHERE & C4. Location choice \\
\hline & To WHO & C5. Mode of outsourcing \\
\hline & To WHO & C6. Pool of providers \\
\hline & To WHO & C7. Provider selection \\
\hline & HOW & C9a. Product/service architecture modularity \\
\hline & HOW & C9c Organisational design modularity \\
\hline & HOW & C9d. Alignment of modularities \\
\hline & HOW & C10a. Information technology flexibility \\
\hline & HOW & C10b. Finance flexibility \\
\hline & HOW & C10c Employment intensity flexibility \\
\hline & HOW & C11a. c11b \& c11c. governance \& control \\
\hline & HOW & C12. Organisational culture \\
\hline
\end{tabular}




\begin{tabular}{|l|l|l|}
\hline IMPLEMENTATION & HOW & C13a. Management through projects \\
\cline { 2 - 3 } & HOW & C13b. Knowledge management \\
\cline { 2 - 3 } & HOW & C13c. Learning management \\
\hline
\end{tabular}

\section{Conclusions}

The primary research question posed by this work was, "how can firms successfully outsource innovation'? This paper has provided a comprehensive response in the form of a generic holistic model of innovation outsourcing. It is explained through statements of correlation between the model's structure and process, and constituent capabilities, to performance. Highlighting the potential benefits of utilising the model enables the following recommendations to be made:

- $\quad$ Make performance the focus of innovation outsourcing aims.

- $\quad$ Adopt a three stage, (selection, deployment, and implementation), process for outsourcing innovation.

- Identify all the innovation activity that can potentially be outsourced and define clear rationales for doing so.

- $\quad$ Align outsourced innovation activity to existing capability.

- Invest in developing capability to outsource potential innovation activity where performance allows.

The model aids effective day-to-day management of outsourced innovation. Prior to the implementation stage of the model, the 'selection' and 'implementation' stages have ensured that, only innovation activity appropriate for outsourcing is selected, and that it is supported by appropriate structures and procedures. The consequence is fewer potential risks and implementation issues, leading to more effective day-to-day management of outsourced innovation. Communication with partners/suppliers is an inherent aspect of outsourced innovation. Due to the incomplete decomposability of knowledge associated with innovation products/services, there exists a risk of inadvertently transferring proprietary knowledge to suppliers in outsourcing relationships. This research identifies that such an issue may be overcome by ensuring that experienced managers always accompany less-experienced employees when meeting with outsourced innovation suppliers.

The model developed by this research describes innovation outsourcing as an open system of interrelated activities that takes firm strategy, (in terms of people, organisational structures, environment, and technology), as its input to transform it into improved firm performance through innovation. This study is the first to consider innovation outsourcing as a system. In doing so, it has enabled a more complete view of innovation outsourcing management than is currently available. Despite innovation outsourcing being a complex multi-faceted concept comprising various characteristics encompassing several theoretical 
foundations, existing studies have tended towards a narrow focus, concerned only with one or a few aspects of innovation outsourcing.

The inductive/deductive descriptive theory-building research design adopted for this study enables the continual development and refinement of the innovation outsourcing model.

Each cycle of inductive theory-building enables the creation of additional categories and associations between innovation outsourcing phenomena. These are then tested in further cycles of deductive theory-building. Anomalies are identified and resolved. Each cycle of the theory-building process has the potential to provide further insights into the model. The innovation outsourcing model developed by this study is largely descriptive with limited predictive powers. Development of a statement of causality to identify what 'causes' performance would provide enhanced predictive powers, guiding managers with actions they ought to take in particular circumstances. A statement of causality is developed through a process of normative theory building which is similar to that for building descriptive-theory, involving steps of observation, categorisation and association.

Observation involves identifying and describing the attributes of capabilities which result in performance. These are categorised according to the circumstances that result in innovation outsourcing performance. The circumstances are considered as a whole to formulate a preliminary statement of causality which is subsequently tested using an explicitly normative form of circumstances analysis, e.g., backcasting.

\section{References}

Amaral, J., Anderson, E. and Parker, G. (2011) 'Putting it together: How to succeed in distributed product development', MIT Sloan Management Review, 52(2): pp. 51-58.

Appiah-Adu, K., Okpattah, B.K. and Djokoto, J.G., (2016), 'Technology transfer, outsourcing, capability and performance: A comparison of foreign and local firms in Ghana.' Technology in Society, 47, pp.31-39.

Aubert, B.A., Kishore, R. and Iriyama, A., (2015) 'Exploring and managing the "innovation through outsourcing" paradox', The Journal of Strategic Information Systems, 24(4), pp.255-269.

Azadegan, A. and Dooley, K. J. (2010) 'Supplier innovativeness, organizational learning styles and manufacturer performance: An empirical assessment', Journal of Operations Management, 28(6): pp. 488- 505.

Baloh, P., Jha, S. and Awazu, Y. (2008) 'Building strategic partnerships for managing innovation outsourcing', Strategic Outsourcing: An International Journal, 1(2): pp. 100-121.

Bengtsson, L., von Haartman, R. and Dabhilkar, M. (2009) 'Low-cost versus innovation: Contrasting outsourcing and integration strategies in manufacturing', Creativity \& Innovation Management, 18(1): pp. 35-47.

Breunig, R. and Bakhtiari, S., (2013) 'Outsourcing and innovation: An empirical exploration of the dynamic relationship', The BE Journal of Economic Analysis \& Policy, 13(1), pp.395-418. 
Busi, M. and Mclvor, R. (2008) 'Setting the outsourcing research agenda: The top-10 most urgent outsourcing areas', Strategic Outsourcing: An International Journal, 1(3): pp. 185-197.

Chang, Y.-C., Chen, Y.-C. and Kuo, T.-K. 2009. Strategic technology sourcing in corporate ventures; a study of Taiwanese pharmaceutical firms, International Journal of Entrepreneurial Behaviour \& Research 15(5): pp. 497-517.

Checkland, P. 2006. Learning for Action, John Wiley \& Sons Ltd., Chichester, UK.

Chesbrough, H. and Crowther, A. 2006. Beyond high tech: Early adopters of open innovation in other industries, R\&D Management 36(3): pp. 229-236.

Chesbrough, H. W. 2003. Open Innovation: The New Imperative for Creating and Profiting from Technology, Harvard Business School Press, Boston, Massachusetts, USA.

Chou, D.C. and Chou, A.Y., 2009. Information systems outsourcing life cycle and risks analysis. Computer Standards \& Interfaces, 31(5), pp.1036-1043.

Ciravegna, L. and Maielli, G. 2011. Outsourcing of new product development and the opening of innovation in mature industries: A longitudinal study of Fiat during crisis and recovery, International Journal of Innovation Management 15(1): pp. 69-93.

Coase, R. 1937. The nature of the firm, Economica 4: pp. 386-405. 36

Cooper, R., Edgett, S. and Kleinschmidt, E. 2001. Portfolio Management for New Products, Perseus Publishing, Cambridge, MA USA.

Cooper, D. and Schindler, P. 2008. Business Research Methods, McGraw-Hill, London, UK.

Cui, Z. and Loch, C. (2011) 'A strategic decision framework for innovation outsourcing', International Journal of Innovation Management, 15(5): pp. 899-930.

Dabrowska, J. and Savitskaya, I., (2014) 'When culture matters: exploring the open innovation paradigm', International Journal of Business Innovation and Research, 8(1), pp.94-118.

Elango, B. (2008) 'Using outsourcing for strategic competitiveness in small and mediumsized firms', Competitiveness Review, 18(4): pp. 322-332.

Festel, G., Cleyn, S. D., Boutellier, R. and Braet, J. (2011) 'Optimizing the R\&D process using spin-outs: Case studies from the pharmaceutical industry', Research Technology Management, 54(1): pp. 32-41

Flipse, S., van der Sanden, M., van der Velden, T., Fortuin, F., Omta, S. and Osseweijer, P. (2013), 'Identifying key performance indicators in food technology contract R\&D', Journal of Engineering and Technology Management, 30(1): pp. 72-94.

Ford, S., Mortara, L. and Probert, D. (2012) 'Disentangling the complexity of early-stage technology acquisitions', Research Technology Management, 55(3): pp. 40-48.

Fritsch, U. and Görg, H., (2015) 'Outsourcing, Importing and Innovation: Evidence from Firmlevel Data for Emerging Economies', Review of International Economics, 23(4), pp.687-714.

Goodwin, P. and Wright, G. (2009), 'Decision Analysis for Management Judgement', John Wiley \& Sons Ltd., Chichester, UK.

Grimpe, C. and Kaiser, U., (2010) 'Balancing internal and external knowledge acquisition: the gains and pains from R\&D outsourcing', Journal of management studies, 47(8), pp.1483-1509.

Grote, M. and Taube, F. (2007) 'When outsourcing is not an option: International relocation of investment bank research - or isn't it', Journal of International Management, 13(1): pp. 57-77. 
Hamel, G. and Prahalad, C. (1994) 'Competing for the Future', Harvard Business School Press, Cambridge, Mass., USA.

Hempell, T. and Zwick, T. (2008) 'New technology, work organisation, and innovation', Economics of Innovation \& New Technology, 17(4): pp. 331-354.

Hinkkanen, J.J., Jääskeläinen, M. and Väätänen, J., (2013), 'The role of competitive pressure in R\&D cooperation: evidence from immature markets', International Journal of Business Innovation and Research, 7(5), pp.619-636.

Howard, R. and Matheson, J. (2005), 'Influence diagrams', Decision Analysis, 2(3): pp. 127143.

Howells, J., Gagliardi, D. and Malik, K. (2008) 'The growth and management of R\&D outsourcing: Evidence from UK pharmaceuticals', R\&D Management, 38(2): pp. 205219.

Hsuan, J. and Mahnke, V. (2011) 'Outsourcing R\&D: A review, model, and research agenda', R\&D Management, 41(1): pp. 1-7.

Jones, E. C. S. and Sims, D. (1983), 'Messing about in Problems', Pergamon Press, Oxford, UK.

Kamuriwo, D.S. and Baden-Fuller, C., (2016), 'Knowledge integration using product R\&D outsourcing in biotechnology, Research Policy, 45(5), pp.1031-1045.

King, N. (2004), 'Using templates in the thematic analysis of text', in C. Cassell and G. Symon (eds), Essential Guide to Qualitative Methods in Organizational Research, Sage Publications Ltd., London, UK.

Lancaster, K. (1971), Consumer Demand: A New Approach, Columbia University Press, New York, USA.

Lowman, M., Trott, P., Hoecht, A. and Sellam, Z. (2012) 'Innovation risks of outsourcing in pharmaceutical new product development', Technovation, 32(2): pp. 99-109.

Mclvor, R. (2005), 'The Outsourcing Process: Strategies for Evaluation and Management', Cambridge University Press, Cambridge, UK.

Martinez-Noya, A., Garcia-Canal, E. and Guillen, M. (2012) 'International R\&D service outsourcing by technology-intensive firms: Whether and where?', Journal of International Management, 18(1): pp. 18-37.

Massini, S. and Miozzo, M. (2012) 'Outsourcing and onshoring of business services: Challenges to theory, management and geography of innovation', Regional Studies, 46(9): pp. 1219-1242.

Mortara, L., Slacik, I., Napp, J. and Minshall, T. (2010), 'Implementing open innovation: Cultural issues', International Journal of Entrepreneurship and Innovation Management, 11(4): pp. 369-397.

Naghavi, A. and Ottaviano, G., (2009), 'Offshoring and product innovation', Economic Theory, 38(3), pp.517-532.

Nambisan, S. and Sawhney, M. (2007), 'A buyer's guide to the innovation bazaar', Harvard Business Review, 85(6): pp. 109-118.

O'Regan, N. and Kling, G. (2011), 'Technology outsourcing in manufacturing small-and medium-sized firms: Another competitive resource?', R\&D Management, 41(1): pp. 92-105. 31, 37, 128

Oshri, I., Kotlarsky, J. and Gerbasi, A., (2015), 'Strategic innovation through outsourcing: the role of relational and contractual governance', The Journal of Strategic Information Systems, 24(3), pp.203-216. 
Paoli, M. and Prencipe, A. (1999), 'The role of knowledge bases in complex product systems: Some empirical evidence from the aero engine industry', Journal of Management \& Governance, 3(2): pp. 137-160.

Penrose, E. (1959). 'The Theory of the Growth of the Firm', Basil Blackwell, Oxford, UK. 37

Piachaud, B. (2002), 'Outsourcing in the pharmaceutical manufacturing process: An examination of the CRO experience', Technovation, 22(2): pp. 81-90.

Prahalad, C. and Hamel, G. (1990), 'The core competence of the corporation', Harvard Business Review, 68(4): pp. 79-91. 38, 270

Prahalad, C. and Hamel, G. (1994), 'Competing for the Future', Harvard Business School Press, Cambridge MA, USA. 38

Quinn, J. (2000), 'Innovation: The new engine of growth', MIT Sloan Management Review, 41(4): pp. 13-28.

Rehman, S., Tiwari, A., Turner, C, (2015), 'Innovation Outsourcing: A review of literature, International', Journal of Technology, Policy and Management, Vol. 15, No. 4, pp. 333-356.

Ritchie, J. and Spencer, L. (1994). 'Qualitative data analysis for applied policy research', in A.Bryman and R. Burgess (eds), Analyzing Qualitative Data, Routledge, Abingdon, UK, chapter 9, pp. 173-194.

Roy, S. and Sivakumar, K. (2011), 'Managing intellectual property in global outsourcing for innovation generation', Journal of Product Innovation Management, 28(1): pp. 4862.

Roy, S. and Sivakumar, K., (2012), 'Global outsourcing relationships and innovation: a conceptual framework and research propositions', Journal of Product Innovation Management, 29(4), pp.513-530.

Stanko, M.A. and Olleros, X., (2013), 'Industry growth and the knowledge spillover regime: Does outsourcing harm innovativeness but help profit?', Journal of Business Research, 66(10), pp.2007-2016.

Teece, D., Pisano, G. and Shuen, A. (1997), 'Dynamic capabilities and strategic management', Strategic Management Journal, 18(7): pp. 509-533.

Tiwana, A. and Keil, M. (2007), 'Does peripheral knowledge complement control? an empirical test in technology outsourcing alliances', Strategic Management Journal 28(6): pp. 623-634

Verwaal, E., (2017), 'Global outsourcing, explorative innovation and firm financial performance: A knowledge-exchange based perspective', Journal of World Business, 52(1), pp.17-27.

Verwaal, E., Commandeur, H. and Verbeke, W., (2009), 'Value Creation and Value Claiming in Strategic Outsourcing Decisions: A Resource Contingency Perspective', Journal of Management, 35(2), pp.420-444.

Waychal, P., Mohanty, R.P. and Verma, A., (2011), 'Determinants of innovation as a competence: an empirical study', International Journal of Business Innovation and Research, 5(2), pp.192-211.

Williamson, O. (1975), 'Markets and Hierarchies', Free Press, New York, USA. 36, 238

Williamson, O. (1985), 'The economic institutions of capitalism: Firms, markets and relational contracting', Free Press, New York, USA. 36, 238

Wouters, M. (2010), 'Customer value propositions in the context of technology commercialization', International Journal of Innovation Management, 14(6): pp. 1099-1127. 
Wu, F., Li, H., Chu, L. and Sculli, D. (2013), 'Supplier selection for outsourcing from the perspective of protecting crucial product knowledge', International Journal of Production Research, 51(5): pp. 1508-1519.

Zirpoli, F. and Becker, M. (2011a), 'The limits of design and engineering outsourcing: Performance integration and the unfulfilled promises of modularity', $R \& D$ Management, 41(1): pp. 21-43.

Zirpoli, F. and Becker, M. (2011b), 'What happens when you outsource too much?', MIT Sloan Management Review, 52(2): pp. 59-64. 
2018-04-02

\title{
A framework for innovation outsourcing
}

\author{
Rehman, Shahwar
}

Inderscience

Shahwar Rehman, Ashutosh Tiwari, Christopher Turner and Leon Williams. A framework for innovation outsourcing. International Journal of Business Innovation and Research, Volume 16, Issue 1, 2018, pp. 79-111

https://doi.org/10.1504/IJBIR.2018.091085

Downloaded from Cranfield Library Services E-Repository 